\title{
Se ThelTLIS \\ Transdisciplinary Artful Doing in Spaces of Experimentation and Imagination
}

Hans Dieleman, Autonomous University of Mexico-City, Mexico, Email: hansdieleman@gmail.com

doi: $10.22545 / 2012 / 00028$

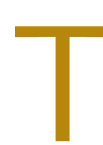
his article links transdisciplinarity with reflective action and artful doing, as well as with the concept of spaces of experimentation and imagination. It argues that artful doing is a genuine transdisciplinary practice that is at once rooted in sensitivity, intuition as well as analytical rationality. It organically links analytical and feelings intelligence with the intelligence of the body. It goes on to show how artful doing can be studied, taught and practiced in spaces of experimentation and imagination. Such spaces invite to explore the world simultaneously on various levels of reality and through various activities such as analysis, introspection, dialogues of knowing, manipulating reality thus constructing alternative realities. The article analysis that working in such spaces implies hybridization of usually separated spheres as art, science, engineering, design, public policy, education, and more. Finally the article focuses on implementing transdisciplinarity in universities and identifies 5 critical aspects in the implementation process.

Keywords: transdisciplinary practice, reflective action, artful doing, experiences, imagination, education.

\section{Introduction}

There is still a lot of confusion around the concept of transdisciplinarity. I realized that after a visit to the new campus of the Autonomous Metropolitan University of Mexico-City, the campus "UAM-Lerma". The following text was written on the wall of the main campus building:

\section{Our reality requires that knowledge will be created through the conjunction of various points of view that together create the scope for transdisciplinary activities}

Yet, the professors with whom I talked - they are working in the transversal research stream of sustainability - had a hard time imaginating how transdisciplinarity could be implemented in the curricula. I noticed that the professors continued thinking in terms of established disciplines and fields of knowledge instead of thinking in terms of processes of knowing or ways to relate ourselves with our environment. Without doubt this has to do with the dominant scientific worldview and its particular way of conceptualizing knowledge, knowing and education. Knowledge is phrased in terms of silos, containers, disciplines or fields of knowledge and education in terms of the transfer of those fields of knowledge. This seriously hampers a clear understanding of transdisciplinarity. Transdisciplinarity is seen as the ultimate step 
in a sequence of the disciplinary $>$ multi- $>$ inter$>$ transdisciplinary whereas every step marks a different way in which the disciplines relate to the object of study. It is correct but yet easily misunderstood.

We talk about multidisciplinarity when various disciplines study, in one project, a problem or phenomena independently from each other. Interdisciplinarity comes into play when the disciplines transfer their methods to arrive at one more integrated understanding of a problem or phenomena. Transdisciplinarity is indeed a next step, but its essence cannot really be understood in terms of the relationship between disciplines and object of study. This immediately becomes clear when we look at the way Nicolescu ${ }^{1}$ defined transdisciplinarity. Transdisciplinarity, he said, concerns that which is at once between the disciplines, across the different disciplines, and beyond all discipline. In other words, it is not so much about disciplines but about that what is "between, across and beyond" those disciplines. Its essence is to unite various ways of knowing and to relate us with the world in a more-than-disciplinary way. Understanding its essence implies leaving the classical scientific worldview with its established concepts of knowledge, knowing and education.

One of the professors at UAM-Lerma asked me more information on how to apply inter- and transdisciplinarity in a typical university setting, and after having returned from my visit I posted this question on the Cultura21 website ${ }^{1}$, a website where artists and academic researchers with interest and experience in transdisciplinary practice unite. I immediately received a lot of feedback and two key words caught my attention while going over all the various comments, recommendations and observations: "sensitivity" and "action". Transdisciplinary practice is - in addition to disciplinary knowing about being sensitive in non-cognitive ways or in the words of Nicolescu about linking feeling's intelligence with analytical intelligence and the intelligence of the body[2]. Transdisciplinarity equally is about knowing through action, as linking the various ways of knowing occurs in action.

The answers I received pointed at my own work on "reflective action and artful doing", as well as on my ideas about working in "spaces of experimentation and imagination" [3] [4] [5]. Yet I never related them in an explicit way to transdisciplinarity. Nicolescu,

\footnotetext{
${ }^{1}$ http://listi.jpberlin.de/mailman/listinfo/international (last accessed November 14, 2012).
}

being included in the mailing list, invited me to write an article for the Transdisciplinary Journal of Engineering \& Science of the ATLAS, The Academy of Transdisciplinary Learning \& Advanced Studies. So I decided to try to link my ideas on reflective action and artful doing in spaces of experimentation and imagination with transdisciplinary practice and education. The result is this article that basically has four parts: 1) transdisciplinarity, 2) reflective action/artful doing, 3) spaces of experimentation and imagination and 4) how to apply transdisciplinarity in a typical university setting. Before diving into the last three parts I first need to present the key elements of transdisciplinarity, in as far as and in the ways that I understand them. I try to do this as short and concise as possible, making extensive reference to the text "Transdisciplinarity, past, present and future" written by Niculescu in $2006^{2}$ After this first part the article explores the links between transdisciplinarity, reflective action/artful doing and education in spaces of experimentation and imagination.

\section{Transdisciplinarity}

In the introduction I mentioned the importance of leaving the classical scientific worldview with its established concepts of knowledge, knowing and education. This is important as transdisciplinarity is based on the theoretical foundations of quantum physics, such as quantum indeterminism and the principle of superposition of quantum. With these principles (among others) quantum physics introduced a world that is very different from the classical world with its mechanical Newtonian and analytical Cartesian logic. The classical scientific worldview sees a world that is ordered by the existence of certain laws that function independently from our own observations, thus claiming the existence of order as well as of objective knowledge and truth. Quantum physics on the other hand, shows a reality that is not at all ordered, but an entity full of ambiguity with processes and relationships that are often conflicting, competing and complementary at the same time. Transdisciplinarity explores the epistemological, ontological and methodological consequences of quantum physics, and discloses a world of complexity

\footnotetext{
${ }^{2}$ The text is available online and published in the book "Moving Worldviews - Reshaping sciences, policies and practices for endogenous sustainable development" (Haverkort and Reijntjes ed., 2006).
} 
and complexity thinking, as in the way Edgar Morin developed this thinking throughout his academic career[6] [7] [8].

Transdisciplinarity is rooted in scientific developments but is certainly not only an academic endeavor. Nicolescu explicitly refers to the important dangers the classical scientific worldview incorporates. "Objectivity", he says, "set up as the supreme criterion of Truth, has one inevitable consequence: the transformation of the Subject into an Object. The death of the Subject is the price we pay for objective knowledge. The human being became an object - an object of the exploitation of man by man, an object of the experiments of ideologies which are proclaimed scientific, an object of scientific studies to be dissected, formalized, and manipulated . . The Man-God has become a Man-Object, of which the only result can be self-destruction" [9]. Cristina Nuez, coordinator of the Master program in "Transdisciplinary Studies and Sustainability" of the University of Veracruz in Jalapa, Mexico adds to this by saying that: "In the Age of Reason, the irrational is more active than ever...if we do not create new relationships with life and within ourselves . . . we will not be able to exist for long as human beings in this planet." [10]. Because of these reasons, transdisciplinarity should be considered as both a transformative process as well as an epistemological, ontological and methodological endeavor.

Werner Heisenberg was one of the first to see the epistemological, ontological and methodological consequences of quantum physics. "The concept of "objective" and "subjective" - writes Heisenberg designate [...] two different aspects of one reality; however we would make a very crude simplification if we want to divide the world in one objective reality and one subjective reality" [11]. Heisenberg also asserted that we make a too strong difference between scientific knowledge that describes the "real" world and other ways of knowing such as artistic, imaginative and spiritual knowing, that deal with not much more than ideas, concepts or experiences. This division has led to the widely accepted idea that "all knowledge other than scientific knowledge is . . . cast into the inferno of subjectivity, tolerated at most as a meaningless embellishment or rejected with contempt as a fantasy, an illusion, a regression, or a product of the imagination" [12]. Quantum physics shows that we need to rethink the claims of classical science such as the total separation between the subject and the object, the assumption that the material world is the only "real" world and the idea that science can develop independently from other sources of knowing such as theology, philosophy, the arts and culture, indigenous or spiritual knowing.

\subsection{The Unity of Knowing in Transdisciplinarity; Axioms 1 and 3}

The transdisciplinary response is that there are different ways of knowing and there is no hierarchy between them. By contrast, the different ways are complementary and - this is a key principle of transdisciplinarity - refer to different levels of reality. The notion of levels of reality is not used in a loose or metaphorical way, but is the very heart of transdisciplinarity and constitutes its key axioms. The first and ontological axiom of transdisciplinarity is that there are, in nature and in our knowledge of nature, different levels of reality and, correspondingly, different levels of perception [13]. Nicolescu, a quantum physicist himself, stresses on numerous moments that the concept of levels of reality - as well as reality itself - is not merely a social construction but that it has a trans-subjective dimension. The concept of levels of reality can be understood by looking at the world of quarks that is guided by different laws and concepts than the world of complex systems. In a comparative way the level of the material world and of traditional scientific knowing is governed by specific laws and concepts, and such is the level of for instance the imaginative world with imaginative and creative knowing and perception. The whole of reality is a complex structure of the totality of levels of reality and corresponding perceptions and every level is what it is because all the levels exist at the same time. No level exists in isolation. This last aspect is formulated in the third axiom of transdisciplinarity, the axiom of complexity.

Thinking for instance in the relationship between man and tree, the various levels of reality and perception can easily be illustrated. On a scientific or material level an important element of our relationship is that trees produce $\mathrm{O}_{2}$ and process $\mathrm{CO}_{2}$ to do so. We humans on the other hand exhale $\mathrm{CO}_{2}$ and need to inhale $\mathrm{O}_{2}$ to survive. This constitutes a symbiotic relationship between us, on one particular level of reality. There are various other levels of reality however where we find other types of relationships. In the course of history trees have served as protection for us against rain and sun. Without doubt they (together with rocks) have triggered our 
imagination and creativity and made us think of the concept of shelter and a roof to protect us from a harsh climate. This constitutes a different level of reality with different laws and concepts (Imagination, associative and lateral thinking, and creativity). Aesthetics is yet another level that makes us see trees as living sculptures with often incredibly beautiful lines, patterns, dimensions and angels. On this level many artists over time were stimulated to paint and sculpt trees, thus trying to explore the essence of our reality. Whenever I (Hans Dieleman) enter a forest and even when I am in the proximity of a few trees, I always and almost immediately feel the relaxing effect that trees have on me. This constitutes a relationship on yet another level, of emotions, with different laws and concepts. And this relationship is equally "real" for me, or maybe even more real because it is what I immediately feel. On a spiritual level trees may represent wisdom and may be moderators that can help us enter in contact with Mother Earth, or help us find wisdom that is otherwise inaccessible.

Is this New Age sentimentality? Transdisciplinarity is not about that but aims to prevent that (I repeat): all knowledge other than scientific knowledge is cast into the inferno of subjectivity, tolerated at most or rejected as a fantasy, an illusion, a regression, or a product of the imagination. The goal of transdisciplinarity is to restore the unity of knowing, not by means of abolishing scientific knowing (or any other form of knowing) but to see all forms of knowing as complementary making up one complex reality.

\subsection{The Object, the Subject and the Included Third; Axiom 2}

One may want to argue at this point: "All this is fine for me, one moment I put on my scientific head, another moment my emotional head and yet in one other moment my spiritual head. This is actually exactly what I do". The point however is not to separate the different levels of reality and knowing, but to integrate them and to find ways to pass from one level to the other. This is another crucial aspect of transdisciplinarity. Its second axiom (the logical axiom) deals exactly with that and states that "The passage from one level of Reality to another is insured by the logic of the included middle". This logic fundamentally challenges classical logic as that is founded on the axioms that $\mathrm{A}$ is $\mathrm{A}$ and can never be non- $\mathrm{A}$ while there is nothing that can be $\mathrm{A}$ and non-
A at the same time. The principle of the included third however states that A can be non-A, precisely because a third is included. But, and this is crucial, A can be non-A at another level of Reality.

This abstract part of the theory of transdisciplinarity is not so difficult to understand when we think of a concrete example. A room for instance can have a table (A) but cannot be without that same table (non-A) at the same time. That is, following classical logic. It is however very well possible that a room has a table and is at the same time without that very same table: it can have a table at the material level of Reality but be without table at the imaginative level of Reality, or the other way around. "Ooh, yes", someone may want to respond . . . "of course, but in that case the table is just there in our imagination, whereas in "reality" it is not (or the other way around)". This response shows how challenging transdisciplinary thinking is! The response clearly sees the "real" reality as the material reality and sees the imaginative reality as "just imagination", The essence of transdisciplinarity - and its huge challenge - is to avoid making a hierarchy among levels of reality and corresponding levels of perception. The level of imagination is as "real" as the material level and therefor the table can be there and cannot be there at the very same time. Apprehending this and making it a familiar part of our understanding of reality is like a quantum leap or paradigm shift away from the classical mode of knowing and seeing the world.

It is not easy and a perfectly understandable question may be: "But then, where is that "reality"? Is it in our brain or imagination (subject) or outside of us (object)?" Nicolescu would answer this question in the following ways: "Knowledge is neither exterior nor interior: it is simultaneously exterior and interior . . . and the included middle logic is the tool for an integrative process. It allows us to cross two different levels of Reality or of perception and to effectively integrate, not only in thinking but also in our own being, the coherence of the Universe" [14]. The use of the included third is a transformative process and [when this integration occurs (HD)] the included third ceases to be an abstract, logical tool: it becomes a living reality touching all the dimensions of our being [15]. The essence of transdisciplinary knowing is the hidden third that is the interaction between the object and the subject trough the transcendence of the subject. This obviously can never occur when the subject is kept out of the process of 
knowing and exploring reality.

Knowledge is not "out there", neither is it "inside of us" and more importantly it is like a "reservoir of infinite potentialities". Where interdisciplinarity aims at "the transfer of methods from one discipline to another"; transdisciplinarity deals with "that which is at once between the disciplines, across the different disciplines, and beyond all discipline". This opens up an immense space of potentially available knowledge, and the essence is that it IS NOT but CAN COME INTO BEING. Nicolescu uses the metaphor of the galaxy to describe the immense space between and beyond disciplines. The separation of disciplines he says is "like the separation between galaxies, solar systems, stars and planets . . When we cross the boundaries we meet the interplanetary and intergalactic vacuum. This vacuum is far from being empty: it is full of invisible matter and energy. It introduces a clear discontinuity between territories of galaxies, solar systems, stars and planets. Without the interplanetary and intergalactic vacuum there is no Universe" [16].

Similarly, disciplines have little meaning when we do not see the spaces between, across and beyond them. When we want to reach a stage of more complete - transdisciplinary - knowledge, we need to explore the vacuum that is full of potential "knowing", find ways to open ourselves to this knowing and incorporate it in a more complete knowledge system. It is here where - in my interpretation - "sensitivity" and "action" come into being, or in other words the unity of analytical intelligence, emotional intelligence and the intelligence of the body. The included third only comes into existence in a process that is inherently "more-than-analytical" through integrating various emotional, imaginative and sensory ways to relate us with our interior and exterior world. It is like that because the other levels of perception (other than analytical/disciplinary) are based on non-analytical laws and ways of connecting us our environment.

The way to achieve the unity of knowing, and here we make the bridge to the second part of this article, is in action and through action. Only in action we can build bridges between different levels of perception and reality, such as our emotions, intuition, our body, our mental and our analytical capacities. It is in action that the hidden third comes into being.

\section{Reflective Action or Artful Doing}

Like scientific research, reflective action is a way to explore reality with the intention to understand it and/or to create a base for taking concrete decisions. But unlike the "classical" - cognitive and analytical - way of exploration, reflective action is at the same time rooted in sensitivity, intuition as well as analytical rationality. It was Nobel laureate Herbert Simon who laid the scientific foundation for the concept of reflective action, even though he did not use the term himself. Simon[17][18] studied how people make decisions when limited information is available, and discovered that we use two different strategies. The first is using logic and ratio, and the second is using heuristics based on intuition and rules of the thumb. Simon observed that many successful managers frequently make decisions using heuristics, and with very good result. Gerd Gigerenzer, writer of "Simple Heuristics That Make Us Smart" [19] and very much working within the tradition of Simon, showed many case studies in which heuristics lead to better decisions than allegedly more sophisticated logical-rational procedures.

It should not be surprising. Using heuristics and intuition are very natural ways of understanding and relating us with the world, and of creating a base for decision making. However, the scientific worldview taught us during the past centuries that "we are because we think" and that we should focus on our cognitive and analytical skills to understand the world. Feelings, emotions and body intelligence were declared to be inferior to analytical intelligence. We decided that emotions interfere in negative ways in "rational decision making" and that it is better to exclude them as much as possible. As a result we unlearned to use our complete potential to relate us with the world, and we lost the ability to function as full and complete human beings. The process of rediscovering our comprehensive and natural potential started with Simon while he analyzed the use of heuristics. He discovered that it means using contextual information and mental maps instead of focusing on the narrow relationship between two variables. These mental maps enable us to see two variables in a wider context thus making decisions in contextual, intuitive and holistic ways. 


\subsection{Mental Maps}

The use of mental maps has been further explored by Chris Argyris and Donald Schön[20][21] and Donald Schön alone [22] [23][24][25] and has led to the introduction off the term reflective action or, in the words of Schön, artful doing. A mental map, Argyris and Schön explain, is like a semantic representation of all the connections the brain makes with respect to a certain situation or problem, and it combines logical thoughts, images and associative thoughts. Every time we have to make a decision, we compare the situation that calls for a decision with similar situations of the past, using our mental map that is like a reservoir of stored images and previous experiences. Schön: "When a practitioner makes sense of a situation he perceives to be unique, he sees it as something already present in his repertoire. . It is . . . to see the unfamiliar, unique situation as both similar to and different from the familiar one, without at first being able to say similar or different with respect to what. The familiar situation functions as a precedent or metaphor" [26]. While taking decisions and performing tasks, we use our reservoir or mental map of previous life experiences, knowledge, feelings, emotions, implicit assumptions, cultural codes of conduct, routines and more. We constantly "map" situations we encounter by comparing them with the maps and images that we have stored in our reservoir of knowledge and experience. In a natural way this combines and integrates various levels of reality and various levels of perception.

Reflective action organically links analytical intelligence, feeling's intelligence and the intelligence of the body. Yet it is not about these three types of intelligence in separation but really about the equilibrium between mind, body and feelings. Schön describes it as follows. Reflexive action is not reducible to knowledge and specific skills and is in fact not reducible to or deconstructable in any separate aspect at all. It is a sequence of actions to achieve a goal and when we know well how to do it, we have difficulty saying how we did it. It is like riding a bike or car, playing a musical instrument, basketball or tennis. It is really an integration of experiences, skills and knowledge in action within an integrated system: the experience feeds the knowledge and the sentiments, whereas the knowledge and the sentiments feed the experience[27].

\subsection{Reflection-in-Action and Reflection-on-Action}

The game of basketball illustrates very well how reflective action works. In order to be able to play basketball we need to know the rules and strategies of the game, as well as certain facts like size of the playing field and meaning of lines drawn on that field (analytical intelligence). But that is not enough. We also need to be sensitive to the opportunities the game offers at certain moments and to take advantage of those opportunities. It is about being sensitive to the movements of the others, both in ones own team as in that of the competitor, and it is about being sensitive to ones own (corporal) possibilities to accelerate, intercept or score. It is all the time using intuition and calculating while the intuition is constantly nourished with the experiences gained through action.

The example of playing basketball show that action is a key aspect of knowing, as is embodiment. It is in action that we go from one level of reality and corresponding perception, to the other. It is because of this that action is so important, as well as thinking in action or reflection in action. Schön introduced a distinction between reflection-on-action and reflection-in-action. Reflection-on-action is having an evaluative moment or session after an activity or task is completed. This is often applied in all kinds of professional settings. Reflection-in-action is different and sometimes described as 'thinking on your feet'. It involves looking - while acting - to our experiences, connecting with our feelings, and attending to our theories-in-use (know-how). It is here where knowing or intelligence cannot be separated from action because knowing and doing are two sides of the same coin in a constant sequence of doing - reflecting - doing again - reflecting, etc.

Schön introduced the word "artful doing" as an alternative to reflective action because it involves a sequence of acts comparable to the one a painter applies while making a painting. The painter adds some color or form to the canvas, takes one step back, overlooks the result, goes back to correct or to add more color or form, takes one more step back, and so on. Schön phrases it as follows: "The practitioner allows himself to experience surprise, puzzlement, or confusion in a situation which he finds uncertain or unique. He reflects on the phenomenon before him, and on the prior understandings which have been implicit in his behavior. He carries out an 
experiment which serves to generate both a new understanding of the phenomenon and a change in the situation" [28].

The concept of reflective action or artful doing has been applied in various fields of knowing, and in particular in the field of organizational learning. The five disciplines in Peter Senge's famous book "The fifth discipline, the art and practice of the learning organization" [29] clearly echoes reflective action and artful doing. The word "art" in the title is not without meaning and refers to the importance of using more than analytical/cognitive rationality. Two of the five disciplines presented in the book are rather standard. They focus on "building a shared vision" and on "team learning". They can be found in virtually any textbook on organizational behavior. The three others however, that give answers on how to build a shared vision and learn in teams, can directly be traced back to the ideas of Argyris and Schön One is called the discipline of "mental models" and is exactly about learning to work with complex mental maps and about learning how to identify them in group work and group decisions. The discipline of "personal mastery" is all about knowing oneself as a complex person and is the "discipline" of functioning as a complex and complete person. The final (or first) fifth discipline is "systems thinking" which is about learning to see in contextual and systemic ways, going beyond simple linear relationships.

I want to make a plea here to also study and apply artful doing or reflective action as a really transdisciplinary practice, as it is an archetypical way to make the hidden third come into being. It is simultaneously intellectual and analytical, constructive and creative, social and communicative as well as sensorial and emotional. It therefor results in a more comprehensive understanding of oneself and of the world in general, and creates a more comprehensive base for decision making in various contexts, private as well as professional. Equally it has the potentially to create various types of knowledge and knowing. It can create "hard" knowledge in the form of data or in the form of practical information or ready-to-use applicable knowing. Yet it also has the potential to go beyond this and to create symbolic and visionary knowing, as well as creative knowing and new ideas, concepts, products or systems. Finally it has the potential, because it links emotions, the body and analytical thinking, to give us (again) control over our own self and our destiny, reducing alienation and disenchantment. As such it has the extremely important transformative potential of, in terms of Nicolescu, changing us back from object into subject thus restoring the Man-God relationship.

Therefor I think it is important to study reflective action and artful doing as a genuine transdisciplinary practice, and to teach it as part of transdisciplinary education. One way to teach, practice and study it is in what I have called spaces of experimentation and imagination.

\section{Spaces of Experimentation and Imagination}

Artful doing or reflective action consists of a sequence of actions, but that by no means implies a linear sequence of very well distinguishable steps. Even though this clearly results from the text above, it is not immediately obvious how to apply it in a real life situation. Almost all projects all over the world - in public policy, in business, in research, in education - use a more or less standard scheme of organizing steps and activities that is based on the sequence of: "Formulate a vision" > "Diagnose the problems" > "Develop alternatives" > "Seek consensus" > "Take decisions" > "Implement and execute". This universally applied scheme is based on the traditional concept that one should think before one act and largely excludes the importance of reflection-in-action. Taking the concept of reflective action serious however, a logical consequence is to change this traditional scheme and replace it with a model that respects the essence of reflection-inaction where thinking and acting are intrinsically linked.

In a number of publications I have proposed to work in "spaces of experimentation and imagination", spaces that do not start with an abstract vision but start at the other end: with the execution. They immediately engage in action and apply the constant sequence of action-reflection-action as a way to simultaneously create vision, diagnose, imagine alternative ways of defining the problem as well as the solution, test and create a shared strategy based on consensus. Such spaces allow and invite to explore reality in various and simultaneous ways such as through analysis, exchanging life experiences, introspection, physically or mentally mimicking or manipulating reality thus constructing alternative realities. They invite to experience puzzlement, surprise and confusion and they seek to transcend existing boundaries[30]. 
Even though spaces of experimentation and imagination are organized around problematic situations their purpose is not to "solve the problem" in a narrow sense but to "engaging in the situation"[31]. This involves entering in contact with them, "talking with them" and seeing how situations "talk back".

Engaging in problematic situations is establishing a relationship with them and to frame them, as well as to frame oneself in relation to that situation. It is like diagnosing, problem definition, visioning and testing alternatives in one and includes at the same time defining ones own engagement with the situation. Schön proposes to actively test various ways to frame and reframe a situation and proposes to develop so-called "generative metaphors" that characterize the situation and generate the way problems are defined. "Through the discovery of new metaphors", he argued, "new perceptions and explanations can be generated". And, "the discovery of new and of generative metaphors is not an act of abstract conceptualization or visioning, but an act of being in contact with, reflecting on and above all experiencing the phenomena"[32]. The essence of experiencing is to contextualize situations and to connect with them while integrating different ways of knowing thus going beyond a mere analytical "diagnose" of a problem. Experiences are the adequate stages for transdisciplinary exploration and practice and for connecting us with the complex world around us integrating - in the words of Gregory Bateson - "hard" data and "soft" data present in any situation[33].

Spaces of experimentation and imagination can take different forms and various rather "classical" spaces are found within the arts. A theatre play is an almost archetypical space of experimentation and imagination, and so are many other art performances and installations. These spaces present "situations", touch upon emotions and feelings and literally invite to reflect in the sense of thinking and rethinking and framing and reframing. Sometimes they also invite to participate, act and co-create, as for instance in the "Theatre of the Oppressed", developed by Augusto Boal[34] and in "Social Sculpture" as developed by Joseph Beuys[35]. Forum theatre (one of the techniques developed by Boal) literary invites members of the audience to replace acting actors thus really reframing the situations acted out during the play. Shelley Sacks, former student of Beuys and now professor at the Oxford Brooks University, created various social sculptures that really "come into being" thanks to the participation of the audience. In the description of her "Landing Strips for Souls" she writes: ". . . I welcome everyone to "the place of questions', outlining some of the choices we are faced with and the need to choose . . . the landing strip is used to welcome souls into the 'imaginative space' of the gathered participants. After a period of silence I open the space for discussion, which is part of the process of reconnecting with the world." 3

Reading a novel equally can create a space of experimentation and imagination, spaces that are primarily mental where the imagination and experimentation is hidden to the eye of an observer. Yet the included third is very real here as well and comes into being as a consequence of the interaction between the book and the reader, as a real hidden third. Meditation as well is a way to open a space of imagination and mental experimentation, on another level of reality and in a very personal way. Games are yet another vehicle to create spaces of experimentation and imagination. Playing games can be helpful to feel and experience complexity and the functioning of complex systems, and thus are valuable tools in transdisciplinary education[36]. Finally, the creation of alternative realities as well is a very adequate form of transdisciplinary action. Nicolescu mentions in his 2005 article a visit to an Eco-village in South Africa and indeed, the creation of such an "alternative community" (like many other social experiments [37]) certainly also can be part of a transdisciplinary exploration of reality, and can thus also be called transdisciplinary reflective action.

Spaces of experimentation and imagination can take other forms as well, and can be created within any sphere of life like public policy, business, research and education. In the field of urban studies, where I currently work, I have come across many spaces of experimentation and imagination. Often the projects do not only work with a generative metaphor but equally use a conceptual approach that helps seeing the various dimensions of the situation simultaneously, thus avoiding a linear approach on just one level of reality. A classical and rather famous example is the project "Mouse Hole" in the city of Rotterdam, the Netherlands ${ }^{4}$ The "Mouse Hole" was an abandoned space in the city where

\footnotetext{
${ }^{3}$ http://greenmuseum.org/c/enterchange/artists/sacks/ (last accessed November 14, 2012).

${ }^{4} \mathrm{http}: / /$ www.publicartonline.org.uk/casestudies/environmen $\mathrm{tal} /$ muizengaatje/description.php (last accessed November 14, 2012).
} 
various problems used to come together such as excessive dumping of waste and prostitution. Yet the space also was hosting an important water treatment system and marked an administrative frontier between two city delegations. Various engineering consultants were invited to create a plan for the redesign of the space and to find a proper place for the water treatment system, respecting the administrative demands of the delegations involved. They all failed as the various demands (technical, administrative, esthetic, ecological) were too conflicting. The project then was adopted by three artists who created a solution that enabled the integration of the various demands. The key difference in their approach was twofold. First of all they did not to focus on the designated problems, but on the area. The literally entered in contact with the area, identifying its typical and positive features and started to create a plan based on those features. The other part was to implement a paradigm change in the way to handle to water treatment system. The engineers all tried to obscure the technology as it was supposed to be ugly, while the artist placed the technology in the center of the space, thus reframing the sense of esthetics and giving the space the recognition it deserved as an important contributor of clean water to the city. The project received various prices for its innovative approach, an approach that can be characterized as a typical example of transdisciplinary artful doing in a space of experimentation and imagination. Chiara Camponeschis book "The Enabling City: Place-Based Creative Problem-Solving and the Power of the Everyday", presents many projects in various parts of the world mainly coming from NGO's, that almost all open spaces of experimentation and imaginating in urban contexts ${ }^{5}$.

Many projects in spaces of experimentation and imagination are "artful" in the sense of working with artistic expressions as theatre, performances, sculptures, music and more, as well as in the sense of being reflective-in-action. In some cases the objective is to create art in the traditional sense of a work of art. In many other cases however, artistic expressions and artful doing are ways of exploration and ways of doing. They may very well result in what we normally call art and they simultaneously result in solutions for problems, new systems or new ways of seeing reality. It was like that in the "Mouse Hole"

\footnotetext{
${ }^{5}$ http://enablingcity.com/wpcontent/uploads/2010/10/the _enabling_city2010-3.pdf (last accessed November 14, 2012).
}

project and is very much like that in the project "Neighborhood Satellites Energy Harvests" presented in Box 1. This as well is a very interesting example of transdisciplinary artful doing in a space of experimentation and imagination currently being realized in Berlin, Germany. In this project the problem of urban $\mathrm{CO}_{2}$-emissions is framed within the generative metaphor of the city as a field of numerous energy crops (emissions) that are out there to be harvested. Reframing the city in such a way opens a whole new range of actions to solve the emissions problem while at the same time establishing new relationships with the city.

A key characteristic of working in spaces of experimentation and imagination is the hybridization of what used to be separated spheres of art, science, engineering, design, public policy, education, urbanism, social work, environmental studies, ecological restoration and much more. It is through this hybridization that we realize transdisciplinary studies and open up the possibility to transcend and make new knowledge and insights come into being. There are probably hundreds of such hybrid projects in spaces of experimentation and imagination around the world, and we should study them as they can teach us how to work in transdisciplinary ways in concrete settings. Probably the only reason we don't do that is because we have not framed them as such. 
The project "Neighborhood Satellites Energy Harvests", developed by the Berlin based artists Hanspeter Kadel and Myriel Milicevic, reframes the city as a field of numerous energy crops that are out there to be harvested. Energy coming from heat produced by electrical equipment like air conditioners, vibration caused by heavy traffic, heat of light emitted in shop windows, or noise coming from a variety of sources as sirens and heavy trucks can all be turned back into usable energy. The artists designed a variety of simple and ingenious harvesters to collect energy coming from light, noise, vibration and heat.

The metaphor that frames the city and its related emissions problem definition unfolds immediately in a variety of actions to be taken on various levels of reality. On a creative level, the artists provide kits with instructions so people can make their own harvesters, and they organize workshops to help citizens to really build them. Simultaneously the citizens, with the help of the artists, make inventories of energy leaks in their neighborhoods, and explore ways to create a local micro-powernetwork using the self-constructed harvesters. In these moments they work in both the analytical as well as the creative levels. During the entire time the project invites citizens to

\begin{abstract}
look in new ways at themselves and at their relationship with the city, giving them the tools to actively interfere in that city, thus taking control and being creative. Finally the project potentially changes the relationship between citizens within their communities.

The harvesters in the micro-power-network really need to function well, or the project will be doomed to fail. The level of technical and analytical reality is crucial, but so is the level of imagination and of being open to new ideas and metaphors. When participants cannot link themselves with the vision that forms the base of the entire project, it will be difficult to have confidence in the project and to be motivated to really go for it results. This capacity to link to such a new and avantgarde reality depends on both ones personal characteristics (and relates back to knowledge of one self) as well as characteristics of the project. The success of such a project really depends on the capacity to link various levels to make it one comprehensive project.
\end{abstract}

Box 1: "Neighborhood Satellites Energy Harvests" as Space of Experimentation and Imagination.

\section{Back to the Question of Inter- and Transdisciplinarity in a Typical University Setting}

This article started with the question asked to me how to implement inter- and transdisciplinarity in a typical university setting. I want to address this question in an explicit way and the first thing to do is to distinguish well between inter- and transdisciplinarity. Nicolescu framed this distinction within the concept of horizontal and vertical complexity[38]. Where horizontal complexity refers to the complexity in one level of reality, for example the material level with its analytical way of knowing, vertical complexity refers to the complexity on various levels of reality. Interdisciplinarity is a way to cope with horizontal complexity while transdisciplinarity aims to address vertical complexity. Interdisciplinarity is a valuable response to the challenge of complexity, but only on one level of reality. Although the inte- 
gration of various disciplines is important, it does not contribute to the important need to unite ways of knowing and restore the links between the object and the subject of knowing. That is why transdisciplinarity is important and fundamentally different from interdisciplinarity. This first of all should be recognized within universities.

Secondly there are changes in knowledge and skills to be considered. Transdisciplinarity requires the range of standard capacities and skills taught within the context of any academic discipline. On top of that it requires communicative and collaborative skills that we normally find in business school but that are certainly not standard in curricula outside of business schools. Beyond these "standard" skills, transdisciplinarity requires capacities and skills on rather different levels of reality and perception. An extensive level of self-awareness and knowledge of one self is important and this involves, besides rationalanalytical skills, skills like daring to rely on intuition, daring to work in iterative schemes allowing oneself puzzlement and confusion, as well as skills that enable (re-) establishing sensatory links with ones body. Therefor training the senses of seeing, hearing, smelling, tasting and touching/feeling is an integral part of transdisciplinary education. Learning to relate ourselves with our environments equally is a challenge that implies capacities of conceptual thinking and the development of generative metaphors as new ways of seeing reality in an experiential way. Finally it involves organizational capacities and skills, necessary to create the conditions to engage in concrete action, as concrete action is needed to make the hidden third come into being, and to connect and unite various levels of reality.

Thirdly, curricula should ensure the integration of the skills and capacities through integrated reflective action or artful doing. Therefor a large - and crucial part of transdisciplinary education should be projectbased and action-based[39]. BUT (!), these projects should include reflective action enabling to change from one level of reality to another. And this calls for project-based and action-based education in spaces of experimentation and imagination. I will illustrate what this means around the concept of the ecological footprint.

Teaching the ecological footprint is a pretty standard element in environmental sciences curricula today. Usually the concept is introduced in an analytical way (presenting foot print categories, energy equivalents, level of the sustainable footprint, etc.) and students calculate their own footprint using a computer. It results in analytical knowing and in a feeling of guilt when the footprint exceeds the margin of sustainability. In 2002 I created a transdisciplinary project around the concept of the ecological footprint, called "Ego-Travels". In this project students really engaged in the situation and were not merely confronted with "a number" (a footprint) but with choices for life that have ecological implications. Yet organizing such a project really involves many changes in the standard way of working and shows us what it means to work at once between and across disciplines, as well as beyond all discipline (see box 2 ).

"Ego-Travels" was an educational project realized in the Erasmus University Rotterdam in 2002. The project aimed at introducing the concept of the ecological footprint using the generative metaphor of the journey of life. The project created a space of experimentation and imagination that was - in the words of Sacha Kagan, one of the participating students - at the same time a (fake) travel agency, a performance, an installation and a party. The metaphor of the journey of life resulted in the idea to create a travel agency where students could book the journey of their life (their ego-travel) thus making them sensitive to the ecological impacts of their lifestyle. The metaphor and concept of the travel agency immediately unfolded various activities to be realized simultaneously: to create a travel agency and a travel guide, to design a house style and logo, to formulate alternative "lifestyle arrangements", to think in terms of payment of such arrangements and link those payments with ecological footprints, to think in terms of marketing of the new agency, of funding, of convincing students and the faculty of the relevance of the concept, and to be open to let students, sponsors or anybody else expand on the original idea.

Thanks to financial support of the Erasmus University and a Rotterdam based Green Shopping Mall the project could be realized and a party-center was rented to organize a party that was announced as the opening party of the new travel agency. Meanwhile the travel guide was produced and the costs 
of the arrangements calculated in ecological footprints of every lifestyle element, thus calculating the ecological costs of the specific journey a customer would choose.

During the party a DJ played ambient music, slide shows showed environmental effects of lifestyles and activities as a garbage contest and a fortune teller added to the environmental "experience". The customers/participants, while entering the center, were invited to "book the journey of their life" and for this purpose a typical travel agency was created with desks, images on the wall and hostesses that persuaded the customers to book their travel. The hostesses then calculated the costs and invited the customers to pay. Payment was in the form of helping to blow up a big balloon that represented the globe and was hanging in the middle of the party. The amount of air the participants/customers needed to add to the balloon corresponded to the ecological costs of the journey they selected: the higher the costs the more air they needed to inflate into the balloon. Obviously the balloon grew rapidly and posed an ever increasing threat of explosion. Yet as in "real" life the party went on . . . until the moment the globe really exploded, showing that the world is not big enough for all our combined lifestyle aspirations.

Box 2: "Ego-Travels", Educational Project Realized in the Erasmus University Rotterdam in $2002^{6}$.

Fourthly, engaging in transdisciplinarity within a university is a personal challenge for professors and students alike. I organized the project together with my students and they needed to engage in many activities that could not be accounted for in strict academic terms. In many ways the project crossed established boundaries and called for an enormous amount of conviction and determination to be realized. Such a project really exceeds that what is normally required from students, a university professor or faculty as a whole. The university professor

\footnotetext{
${ }^{6}$ http://sachakagan.chez-alice.fr/sust1024.htm (last accessed November 14, 2012)
}

remains professor but converts into a project manager at the same time. The student remains student but is a member of a workforce as well. Colleagues frequently look at such a project with suspicion and sometimes with disdain as "it is not academic", and does not meet academic standards. Finally it is experimental and reflective and not at all straight forward or linear. As a responsible I was all the way confronted with uncertainty and puzzlement, not knowing (and not being able to know) if the project would end in a success or a big failure, equally not knowing how to define "success" nor "failure".

Professors only can teach in such spaces when they themselves know how to link analytical intelligence with feelings intelligence and the intelligence of the body. They themselves need to dare to work in iterative and reflective - artful - ways and allow themselves puzzlement and confusion. It is a big step for a university professor that is used to work with his or her cognition and feels comfortable in a university precisely because it is a temple of analytical activity. That is why training professors in transdisciplinary artful doing is extremely important, and this training obviously can only be realized in spaces of experimentation and imagination.

Fifthly, the university as institution will need to make changes. It is important that universities create spaces within the curricula to engage in transdisciplinary practice, and designate professors who feel comfortable working in these spaces. The key in realizing this is, as almost always, engaging in a dialogical process that simultaneously involves initiatives at the top of the university as well as on the bottom[40]. Starting at the bottom however is crucial as experience with real transdisciplinary practice in spaces of experimentation and imagination certainly will reduce the confusion that still exists around the concept of transdisciplinarity, and will open ways to institutionalize it and change our universities.

\section{Concluding Remarks}

I like to finish making a reference to Mary Catherine Bateson's book "Peripheral visions: Learning along the way" [41] (M.C. Bateson, 1994). The book is about how we make sense of life and Bateson's answer is that we all the time make connections between seemingly random events and experiences, thus finding the underlying patterns. She makes a 
plea to organize education as much as possible in this same "natural" way: experience based, spiral and "along the way". Often we do not understand all we experience in life, she says, and many experiences result in memories that are stored while only partly understood. New experiences however may put the stored ones in perspective so we later understand what we had not understood before. Because of that it is important to learn to make meaningful connections between different life experiences, and to find the underlying patterns. She describes her own book as "a book of stories and reflections strung together to suggest a style of learning from experience". The book possibly shows the challenge that transdisciplinarity is placing on universities: to organize them as experimental and imaginative spaces for analysis, stories and reflections strung together in random ways thus stimulating a spiral and natural way of learning along the way.

\section{References}

[1] Nicolescu B., 2002. Manifesto of Transdisciplinarity. Albany : State University of New York Press.

[2] Nicolescu B., 2006. Transdisciplinarity, past, present and future, published in: Haverkort Bertus and Coen Reijntjes ed. (2006): Moving Worldviews - Reshaping sciences, policies and practices for endogenous sustainable development, COMPAS Editions, Holland, p. 142-166; page 18.

[3] Dieleman H. y Juarez, M., 2008. Cómo se puede diseñar educación para la sustentabilidad?, in: Revista Internacional de Contaminación Ambiental, 24 (3-August), Universidad Nacional Autnoma de México.

[4] Dieleman H. 2011. Las competencias del quehacer artstico y el conocimiento artstico en la Educacin Superior, in: Pedro Medelln Milán et al (2011): Un Mundo en Transición: Perspectivas de SustentabilIdad para la Educacin Superior, La Editorial Universitaria Potosina.

[5] Dieleman H., 2012. Resilient cities and organizational learning; stimulating eco-cultural innovations. Journal of Cleaner Production, Special Volume "Advancing sustainable urban transformation" edited by Kes McCormick, Lena Neij, Stefan Anderberg, Lars Coenen, Elsevier Publishers, Volume 38.

[6] Morin E., 1973. Le Paradigme perdu: la nature humaine. Paris: Seuil.
[7] Morin E., 1992. Method. Towards a Study of Humankind. Volume 1: The Nature of Nature. New York: Peter Lang

[8] Morin E., 1996. Introduccin al pensamiento complejo, Gedisa, Barcelona.

[9] Nicolescu B., 2006. Transdisciplinarity, past, present and future, published in: Haverkort Bertus and Coen Reijntjes ed.: Moving Worldviews - Reshaping sciences, policies and practices for endogenous sustainable development, COMPAS Editions, Holland, p. 142-166; page 3 .

[10] Núñez M. C., 2011. Sustainability and Spirituality: A Transdisciplinary Perspective, en: ATLAS, Transdisciplinary Journal of Engineering \& Science , 2, page 81 .

[11] Nicolescu B., 2006. Transdisciplinarity, past, present and future, published in: Haverkort Bertus and Coen Reijntjes ed.: Moving Worldviews - Reshaping sciences, policies and practices for endogenous sustainable development, COMPAS Editions, Holland, p. 142-166; page 3 .

[12] Ibid, page 3.

[13] Ibid.

[14] Ibid, page 14 .

[15] Ibid, page 10 .

[16] Ibid, page 5.

[17] Simon H.A., 1955. A Behavioral Model of Rational Choice, quarterly journal of economics, p. 69.

[18] Simon, H.A., 1972. Theories of bounded rationality. In C.B. McGuire and R. Radner (Eds.), Decision and organization: A volume in honor of Jacob Marschak (Chap. 8). Amsterdam: North-Holland.

[19] Gigerenzer, G., Todd, P.M., 1999. ABC Research Group, Simple Heuristics that Make us Smart. Oxford University Press, Oxford.

[20] Argyris, M. and Schön, D., 1974. Theory in Practice. Increasing professional effectiveness, San Francisco: Jossey-Bass.

[21] Argyris, C., \& Schön, D., 1978. Organizational learning: A theory of action perspective, Reading, Mass: Addison Wesley.

[22] Schön, D., 1979. Generative Metaphor: A Perspective on Problem Setting in Social Policy. In A. Ortony (Ed.), Metaphor and Thought. Cambridge: Cambridge University Press. 
[23] Schön, D. A., 1983. The Reflective Practitioner: How professionals think in action. London: Temple Smith.

[24] Schön, D. A., 1985. The design studio: an exploration of its traditions and potentials, London : RIBA Publications for RIBA Building Industry Trust.

[25] Schön, D. A., 1991. The Reflective Turn: Case Studies In and On Educational Practice, New York: Teachers Press, Columbia University.

[26] Schön, D. A., 1983. The Reflective Practitioner: How professionals think in action. London: Temple Smith; p. 138.

[27] Ibid.

[28] Ibid, page 68 .

[29] Senge P.M., 1990. The Fifth Discipline: The Art and Practice of the Learning Organization. New York: Doubleday Currency.

[30] Footnotes 3,4 and 5.

[31] Schön, D. A., 1983. The Reflective Practitioner: How professionals think in action. London: Temple Smith, p. 15.

[32] Schön, D., 1979. Generative Metaphor: A Perspective on Problem Setting in Social Policy. In A. Ortony (Ed.), Metaphor and Thought. Cambridge: Cambridge University Press, p. 259

[33] Bateson, G., 1973. Steps to an Ecology of Mind: Collected Essays, in Anthropology, Psychiatry, Evolution and Epistemology, London: Paladin, Granada, pp. $250-279$.

[34] Boal, A., 1979. The Theatre of the Oppresse, New York: Urizen Books.

[35] Harlan Volker, ed., 2004. What Is Art? Conversation with Joseph Beuys. Clairview Book.

[36] Dieleman H. y Donald H., 2006. Games by which to learn and teach about sustainable development: exploring the relevance of games and experiential learning for sustainability. Journal of Cleaner Production, 14(9-11), pp. 837-847.

[37] Dieleman, H., 2007. Cleaner production and innovation theory; social experiments as a new model to engage in cleaner production, Universidad Metropolitana, Revista Internacional de Contaminacin Ambiental, Mexico DF, Vol. 23(2), pp. 79-94.

[38] Nicolescu B., (ed.), 2008. Transdisciplinarity - Theory and Practice, Hampton Press, Cresskill, New Jersey.
[39] Adame D. 2011. From a Disciplinary to a Transdisciplinary Vision of the University: A Space of Knowledge, Culture, Art, Spirituality, and Life. Transdisciplinary Journal of Engineering \& Science, Volume: 2 (December), page 39.

[40] Ibid, page 39 .

[41] Bateson, M.C., 1994. Peripheral visions: Learning along the way. New York: Harper Collins.

\section{About the Author}

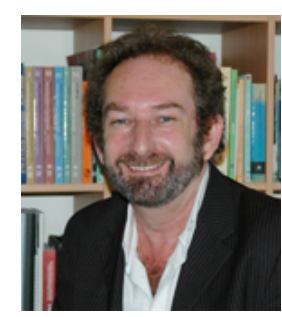

Dr. Hans Dieleman is full professor at the Centre of Urban Studies (CEC) of the Autonomous University of MexicoCity (UACM), where is responsible for the research line in urban sustainability, culture and the arts. He also sits on the board of the College of Sciences and Humanities of that university. He is a member of the team currently developing a doctoral program in Transdisciplinarity and Dialogue of Knowing in the University Veracruzana in Jalapa, Mexico. He is a member of the international coordination team of Cultura21, an ONG that promotes sustainability as cultural change.

Copyright (c) 2012 by the author. This is an open access article distributed under the Creative Commons Attribution License (https://creativecommons.org/licenses/by/4.0/), which permits unrestricted use, distribution, and reproduction in any medium, provided the original work is properly cited. 